\title{
Youth in South Africa Bond with Radio
}

\author{
Maurice Odine \\ Gulf University for Science \& Technology, P.O. Box 7207 Hawally, 32093, Kuwait
}

Received: August 20,2014 Accepted: September 1,2014 Available online: September 23, 2014

doi:10.11114/smc.v2i2.495 URL: http://dx.doi.org/10.11114/smc.v2i2.495

\begin{abstract}
South Africa's youth have found voices through radio as a result of liberalization laws enacted during the post-apartheid democratic period under Nelson Mandela. Today, youth communicate their concerns thanks to the dynamic duo with radio, a medium that penetrates the hinterland and is received in rural areas. To youth, radio is a companion they trust. They listen to radio programs that are produced and presented by children from the children's perspective. Partnerships such as the Children's Radio Foundation (CRF), United Nations Children Fund (UNICEF), United Nations Educational, Scientific and Cultural Organization (UNESCO), German-South African partnership, and government and local entities support youth radio through training and by providing necessary resources. Community and college radio stations, too, have been pivotal in embracing youth radio. Additionally, youth radio participates in simultaneous international live broadcasts with stations in Accra (Ghana), Nairobi (Kenya), and Chicago (United States). Youth radio success is further exemplified by 2009 and 2010 UNICEF Children's Radio Broadcasting Award. The drama, "Shuga Radio," leads in the category, while discussion groups express youth interests. Meanwhile, youth radio-motivated Kwaito music has won the minds of listeners.
\end{abstract}

Keywords: radio, youth, training, children, broadcasting, partnership, empower

\section{Introduction}

When humans take sail or to the air, they are propelled by wind in the atmosphere. Likewise, when birds take to fly, they are aided by wind that cuts through the atmosphere. In the atmosphere, therefore, are airwaves that, incidentally, are associated with radio waves. So, if humans can sail or fly, and if birds can fly amidst airwaves, then youth (including South Africa's) can use radio waves in the form of youth radio. To the curious youth, radio waves are free because they are celestial. Thus, denying genuine, good-natured use of radio waves would be an affront on youth. It is these celestial radio waves that have given voices to South Africa's youth. Denying youth the use and exploitation of radio waves is akin to denying them nature's free oxygen.

Once upon a time the youth in South Africa listened to bird song, then transitioned to the sound of music played on radio. Other radio program types included news, sports, and public affairs. But radio programming, irrespective of the radio station, was conceived by adults and presented by adults. Hence, the available limited children's programming was conceived by non-children and without children's input. This explains why children continued to be largely "excluded" from radio content.

To compound children's radio isolation, television has remained an elite medium. The set is usually placed in a conspicuous corner or section of the house with adorned chairs and accessories mainly prescribed for adults and "respectable" visitors. In other words, children are not to be found nearby, as they are mostly restricted to their own quarters. The inadequate children's programs do not gain wide viewership among the target audience because children do not have direct access to the television set or are completing tasks or chores.

In the case of newspapers, readership is a problem. Children are still learning how to read and write; hence their reading skills lack readership capacity and comprehension. To add woes to children, the stories and analyses are written by adults, from adults' frame of reference and, sometimes, cognitive dissonance.

Yet, youth in South Africa are resilient. Many of them have lived under apartheid, a racial white-only form of government that favored whites at the expense of blacks. In today's new nation, South Africa's youth are benefitting from the fruits of the rainbow nation in which whites, blacks, Indians, Chinese, coloreds no longer consider race as a societal hindrance. In new South Africa, it behooves youth to forge the foundation for tomorrow's leaders. It is this recognition that warrants utilizing the appropriate medium of communication. 
Astute and forward-looking, youth have recognized that, media are too important to be taken lightly or for granted. Fortunately, and unlike television and newspapers, they have found radio as the medium of their time. Radio's ubiquitous outreach, coupled with the low cost of radio sets, is music to the ears of youth. In the meantime, radio production costs are so marginal that South Africa's youth would be "foolhardy" not to take the bait.

It is true that, youth in South Africa bond with radio. The Merriam-Webster dictionary defines bond as "to form a close relationship through frequent association (as the new mother "bonded" with her child). In concurrence, the Oxford English dictionary states that, a bond is "a force or feeling that unites people; a shared emotion or interest." The interactive "force" or "feeling" underscores the bond between South Africa's youth and radio. It is a dynamic duo. Radio is to South Africa's youth what marble is to the sculptor.

In an environment where there is no bond, adults do not shy away from such expressions as, "They are just children," or "They will learn when they grow up," or "They don't know." But children will be children; they are anxious and will ask questions. Ashwin (2014) comments under the headline, "Global Citizenship: Communications." The writer is cognizant of a world culture in which information technology is moving toward an unfettered global environment. Ashwin warns, though, that humans can become more isolated than before. "The rate of advance in human technology ... so in terms of spreading the message, the world has become a smaller place," Ashwin affirms. The writer decries excluding children in society's media agenda.

In 2013, the Farese Family Foundation sponsored a Youth Radio initiative to underscore the importance of media literacy. The initiative provided training in journalism, digital media, and new technology. It was equally the foundation's position that, youth radio is a force for participatory citizenship in inspiring debate about issues pertaining to young people and their communities. Irrespective of communities, children often play together; they fight, too. They learn as they grow. Their eyes are on youth radio and how they can become involved to make a difference.

In South Africa, CRF believes children can make a difference through radio. In 2011, only six percent of Africans accessed the Internet. Conversely, more than 80 percent listened to radio. CRF asserts, "Radio is on the Rise," noting that community radio is taking hold across Africa. Radio listening on the continent grew by 1,386 percent between 2000 and 2006. Besides, young people easily learn production techniques and broadcast skills.

In reality, youth-radio bond is "magical." It motivates youth to become part of reporting that considers them as target audience, giving them power to conceptualize and disseminate youth programs to inform, educate, and entertain. Radio programming for youth, by youth, and for youth is a novelty in South African society. It is too simplistic to describe the youth-radio bond as special. It is, really, a "dynamic duo."

The "duo" has gained popularity in South Africa's communities for obvious reasons. Under apartheid, the country had only two independent radio stations. With new administration came deregulation, which paved the way for a proliferation of commercial and community radio stations. There are currently about 200 community stations, including youth radio stations. Main commercial stations are Metro FM, Jacaranda FM, East Coast Radio, Yfm, 5FM, 94.7 Highveld Stereo, Kaya FM, Good Hope FM, Algoa FM, 702 Talk Radio, 567 Cape Talk, Classic FM, Kfm, OFM, Radio 2000, and Channel Africa. Commercial radio stations broadcast minimal youth content.

\section{Literature Review}

\subsection{Foundation of Broadcasting in South Africa}

Cognizant of the enormous power of electronic media, the African National Congress (ANC) and other political parties took steps in 1990 to alter the monopoly previously enjoyed by the South African Broadcasting Corporation (SABC). The political wave attracted petitions and protests in which academics, church groups, youth organizations, and trade unions participated. Subsequently, an independent board was appointed to run broadcasting affairs in South Africa, leading to the creation of the Independent Broadcasting Authority (IBA). Since 1994, IBA has awarded licenses to diverse groups, resulting in more than 100 community radio stations. In 2005, the newly formed radio division had 11 full spectrum radio stations, a regional KFM, a community XK FM, Lotus FM, Radio 200, and multilingual SABC 1 SABC 2. Earlier in 1996, IBA privatized six lucrative commercial radio stations: Highveld Stereo in Gauteng; Radio Jararanda in Gauteng; East Costal in KwaZulu Natal; KFM in Western Cape; Radio Algoa in Eastern Cape; and OFM in Free State. As an incentive, and to make the airwaves available to previously disadvantaged black populations, the government provided start-up costs totaling 455 million dollars to owners of newly acquired commercial radio stations.

Meanwhile, a 1999 Broadcast Act was enacted to address broadcasting issues outside IBA jurisdiction. For instance, the Act included managing diversity, nation building, education, delineation of roles in formulating broadcast policy, and technological adaptability within the country's broadcasting infrastructure. In 2005, the South African parliament passed the Electronic Communications Act enshrining the following into law: convergence of telecommunication and broadcasting regulation-making processes; replacement of existing telecommunications and broadcasting licensing 
regulations with single license process; and enhancement of IBA's authority to mediate during disputes and market share issues. www.nab.org.za/broadcast.asp admits that community radio stations face financial problems due to lack of advertising revenue, but acknowledges that the stations form the core of training South Africa's radio youth talent.

\subsection{South Africa Radio Listeners}

According to www.southafrica.info, Metro FM, one of South Africa's commercial radio stations, "broadcasts youth culture programming to hip young black city dwellers - and some pretty hip youngsters of other races." With almost 15.4 million radio sets in the country, and with more than 30 million listeners, radio stations disseminate a range of program types, from "ultra-hip" urban music to community news and information in rural areas. Listeners can listen to radio via satellite or on mobile phones via the Internet. The stations also offer live audio streaming that listeners can access from designated websites. There are currently 111 radio stations in South Africa that listeners can listen online. In Joburg there are 19 radio stations; Cape Town, 13; Port-Louis, 12. On the marginal side, there are two stations in Bloemfontein; four stations in Windhoek; and one in Bisho.

As a public service, the country's 11 official languages get airtime, as well as German, Hindi, Portuguese, and the San languages of !Xu and Khwe. Radio stations fall into three categories: public service broadcasting, commercial broadcasting, and community radio stations. The country's public service broadcaster is SABC. While wholly owned by the state, the corporation is financially independent of taxpayers' money, deriving its income from advertising and license fees. As per prevailing mandate, the corporation is to provide both commercial and public service (each administered separately) with commercial radio service in order to subsidize the public service stations. SABC commercial stations include 5FM (national youth music station), Metro FM (music station targeting black youth), and Channel Africa (an external radio service broadcasting in several languages across the content). SABC also makes content available to radio stations of South Africa's Indian (Lotus FM) and X-K-FM to San communities.

From 1994 onwards, community radio stations have seen significant growth in post-apartheid South Africa. The nearly 200 community radio stations are independent, non-profit, and community-based. Combined, they broadcast to about nine million listeners a week. For instance, whilst 410,000 listen to Jozi FM in Joburg, only 2,000 people listen to Radio Unique in the Eastern Cape towns of Aliwal North and Molteno. To improve programming and management, many community radio broadcasters are represented in the National Community Radio Forum founded in 1993 to lobby for diversification of airwaves and to promote development and growth in the radio sector. Of the 120 members on the forum, 88 are on-air radio practitioners.

\subsection{Young (Radio) Reporters Network}

Emma de Villiers (2013) reports that, half a million children die in the country each year due to diseases associated with diarrhea and pneumonia. The children's lives would be saved, the writer contends, if handwashing interventions were in place. UNICEF sponsored the Young Reporters Challenge in 2013 in response to the health hazards. Ahead of October 12 Global Handwashing Day, UNICEF and the Unilever Foundation "challenged" the Young Reporters Network to develop innovative radio programming to promote handwashing. Youth radio reporters from seven community radio stations rose to the challenge. The young reporters produced radio features and conducted live interviews articulating the importance of handwashing and taking seriously their role as "handwashing ambassadors."

A group of young reporters from a community radio station in Atlantis (near Cape Town), better known as "Teen Express," won the grand challenge prize. One of the greatest strengths of Young Reporters Network is the ability of reporters to speak directly to issues affecting their communities. Instead of a generic message on handwashing and sanitation, young people produced and presented inserts relating to specific issues within their communities.

On challenge day the voice on the radio was that of a teenage girl. It is a voice that speaks with authority, challenging a male friend about his handwashing practices. As the public service announcement (PSA) is playing on a community radio station in South Africa's Western Cape province, a group of community members are listening attentively. "Handwashing is such an important practice, but one that is often neglected by members of our community," says youth radio facilitator, Neorisha Julius. "Saving lives and preventing disease is as simple as washing your hands with soap, and as young people we wanted to be ambassadors for this life-saving message."

\subsection{Radio Manifesto}

Broadcasting maximal youth content is the task of youth radio. As a scout, young people make a promise: "On my honor, I will do my best ...." In youth radio, young people do not make a promise. Instead, their work is governed by a Radio Manifesto, which is an "address by young people from around the world to radio broadcasters everywhere." The manifesto is a product of the World Radio Forum (2014) comprised of broadcasters, producers, journalists and trainers in concert with radio stations and advocates of youth radio.

The manifesto states that, "Any radio station that claims to be serving the interests of the community and representing 
the democratic values of society, has to integrate children and youth into their programming." The issue, according to the manifesto, is not youth programming. Rather, it is to allow youth to express their voices and to acquire the experience and commitment to become opinion leaders and responsible citizens.

It is an established fact that young people cannot vote. Notwithstanding, the fact that they "take on the radio waves" is a logical consequence of democratization. And while certain rights may be restricted owing to their age, youth are the pivotal force in a society that plans ahead. The manifesto articulates: "The more responsibilities they [youth] have in participating in community life, the more today's youth will become leaders of tomorrow's communities and nations."

Alfonso Gumucio-Dagron (2014) makes a noteworthy observation. In the view of the writer, young people still have many attributes that are not necessarily inherent in adults. These attributes include integrity, optimism, faith in the future, and commitment to human values, creativity, and enthusiasm. Providing children with the opportunity to communicate these values and attitudes through radio, contends Gumucio-Dagron, is a win-win for communities. Zane Ibrahim, managing director of Bush Radio (Cape Town, South Africa), refers to the Radio Manifesto as a clarion call for youth to express themselves through radio. The radio practitioner adds that, youth broadcasters bring children's rights into the public agenda. Cecilia von Feilitzen of the International Clearinghouse on Children, Youth and Media, admits that many staff members of youth radio are from low-income communities. The director believes, "The media often shows [sic] us the problems of children's lives. Now, these young broadcasters are showing that they want to be, and that they can be part of the solution."

\subsection{Youth Radio as Empowerment}

Youth are excited about dealing with problems that affect them. They jump at the prospect of radio content aimed at positive change. The Radio Workshop Show airs nationwide and is available online, accompanied by a podcast in iTunes. The show features a mix of current affairs, entertainment, information, and showcases stories children can relate to. Broadcasts include advocacy for a local library, audio profiles of young refugees, profile of an architect, a medical doctor responding to questions, and conversations with youth about dedication and motivation. These programs are designed to inspire and nurture a generation of youth leaders.

Sustenance from UNICEF and CRF has facilitated youth radio dialogues on citizenship and social change. Since 2009, the partnership has produced and disseminated a series of radio programs marking the Convention on the Rights of the Child anniversary. And as part of UNICEF climate change initiatives, CRF has trained more than 200 young radio journalists from 44 countries at the Children's Climate Forum in Copenhagen (Denmark) and UNICEF Children's Climate Conference in Zambia. In the program, "World Cup in My Village," CRF and UNICEF conducted radio training for youth to gain access and report on the 2010 World Cup in South Africa.

CRF is relentless in using partnerships as a mechanism for youth radio. The foundation has succeeded in working with South Africa's Basic Education. Together, they have created the Youth Radio Network to "give children a voice." The CRF-Basic Education alliance offers a platform for youth to communicate their views. CRF, UNICEF, and Basic Education subscribe to the notion that, having young people speak about their own problems is expedient "participatory governance." This imperative is paramount since children account for 37 percent of the population, which indicates radio must have youth content. Yet, the reverse is often the norm. For example, while violence in schools and teenage pregnancy are issues that affect young people, the reportage is usually from the adult's perspective. Youth voices are rarely heard or solicited.

\subsection{Community Radio Stations}

The quest to serve youth problems or concerns has given rise to community radio stations. To ensure the population is served by radio, the new government has authorized FM (frequency modulation) transmission thanks to liberalized broadcasting regulations. A prime example is the Greater Lebowakgomo FM station in Limpopo Province. The station broadcasts weekly radio shows that are researched, written, and produced by young people reflecting views about what is happening in their community.

Another characteristic of community radio is learning. Youth are taught how to conduct interviews, debate, create and structure stories, and how to package materials for broadcast. Listeners hear directly from youth about youth issues. To accentuate listener loyalty, youth broadcasters present programs that "brim with authentic, honest feeling." Why not? Youth are yet to entertain manipulation, bias, editorializing, or ulterior motive. Youth programs present simple truth, stating the facts as they are. Success of the Greater Lebowakgomo FM has sparked replication in other parts of South Africa. 15-year old community radio intern, Mashoto Mphahlele, is filled with pride. He boasts of his experience: "For the first time in my life, I feel I can express myself and really get out of my shell."

\subsection{Youth Radio on Youth Economics}

Anders Kelto reports on a US National Public Radio (NPR) story entitled, "Over Half of Youth Unemployed in South 
Africa," that aired on May 28, 2012. The story is relevant. South Africa's youth unemployment rate is 24 percent in a country where 73 percent of the population is under the age of 35 . To many, the youth predicament is not unacceptable; it presents a "time bomb." Despite the calamity stacked against youth, political parties do not refrain from vigorously wooing this segment of the population during elections or for party affiliation.

US reporter, Melissa Block, is on the air: "Now to South Africa and the problem of huge unemployment. The situation is especially severe for young people ... the jobless rate has caused widespread protests and calls for radical economic reform." Reporting from Cape Town, Anders Kelto went to Cape Peninsula University of Technology campus to report on the economic conditions that youth face in South Africa. Here is a sample of youth responses:

- They're not doing anything. They're not creating any jobs. They promise us every year that they're going to create more jobs, but they don't.

- Many of the people I studied with have graduated already. And most of them are still looking for jobs.

- It's a proposal to subsidize employers who take on young workers. But it does nothing to prevent those employers from getting rid of an equal number of older workers.

- They took our land for free. They enslaved our forefathers. We must be given back the mines. We must be given back our land.

\section{Method}

The paper sought to chronicle the paramount pervasiveness of radio in South Africa, and with particular reference to researching and producing programs with youth as target audience. In this regard, other media, such as newspapers and television, were reviewed and evaluated to determine to what extent transmitted (television) or published (newspapers) content addressed youth concerns and problems in the country's communities. It is this central premise that enthralled the ensuing research.

To this end, qualitative content analysis was employed. As stated by Mayring (2000), the methodological approach consists of systematic text analysis, the object of which includes transcripts of recorded interviews and discourses. Krippendorff (1969) concurs "content analysis is the use of replicable and valid method of making specific inferences from text to other states or properties of its source." The paper took advantage, too, of the basis of content analysis laid out in the 1920s and 1930s by Paul Lazersfeld and Harold Lasswell and later published in a book by Berelson (1952). Thus, texts from journals, books, interview transcripts, magazines, and websites were carefully reviewed and evaluated as a process of content analysis.

The two-step flow gave the study a theoretical framework. Katz and Lazersfeld, in their book, Personal Influence, and published in 1955, assert that receiving a message does not imply responding to it. This is when opinion leaders come in. The theory is useful in that, "there are some amongst the media audience who act as opinion leaders." And the appropriateness of the theory lies in the fact that, opinion leaders use the mass media more than the average citizen; mix more than the average across social classes; see themselves (and are seen by others) as having influence on others.

Secondary sources were consulted in researching the paper. These resources included books in library stands, magazines, online resources, Web sites, and newspaper articles. The sources proved useful as foundation for interpreting and analyzing content. Primary sources were also consulted. In this case, the author's travel to Kenya, Cameroon, and Zambia proved invaluable. In addition, 15 phone interviews were conducted between February and March 2014 with South Africans living in Kuwait and with direct knowledge and/or experience with media and audiences in South Africa.

The paper addressed eight topics. Topic one was to examine the underpinnings that keep youth radio functioning as a respectable and organized entity. Topic two looked at the extent to which youth radio has empowered young children. Topic three considered community radio stations and their support of youth radio. Topic four delved into early days of youth radio in view of South Africa's post-apartheid non-racial democratic nation. Topic five assessed the foundation for youth bond with radio. Topic six traced training programs designed to ensure requisite skill development for young broadcasters. Topic seven observed specific programs produced by youth radio for youth audiences. And topic eight gauged the future of youth radio.

In addressing topic one, it was desirable to investigate the factors that make youth radio accepted in the community. In topic two, the paper explored successful program types that have given voices to young people. Topic three studied youth radio support by community radio stations through training or internships. In topic four, a review was undertaken of steps to encourage youth radio in post-apartheid South Africa. Topic five chronicled initiatives and activities that have created the special youth-radio relationship. Capacity building and skill development to sustain youth radio 
broadcasting were tackled in topic six, while topic seven centered on specific radio shows and program types researched and presented by youth radio. And topic eight viewed the continuance of youth radio in light of anticipated population growth that comes with the need to address young people's problems or concerns.

\section{Discussion}

\subsection{Genesis of Youth Radio}

The goal to move youth radio to greater achievements prompted the Department of Education (2001) to increase community radio partnerships. An early success story was Bush Radio in Cape Town. The station broadcast a series of youth radio benefits during the annual "Radio Kidogracy" conference that year. In 2000, the South African Charter on Children's broadcasting held youth discussion groups during the inaugural ceremony of Children's Youth Radio Manifesto. Consequently, youth radio groups sprung in other communities within the country. Youth radio grew rapidly owing to additional support from the European Children's Television Center, Save the Children International Alliance, Plan International (West Africa Regional Office), and Children as Partners Alliance (CAPA). These international entities have allied with the government to establish youth radio's standing and credibility.

\subsection{Youth Radio in Children's Lives}

Youth radio's credibility cannot, though, be taken for granted. Although youth listenership is an important consideration, it is not automatic. Fortuitously, children do listen to radio. They listen in the homes and in the neighborhood. Children also form part of in-car radio audiences as they drive in the company of adults listening to news, analyses, and commentary. Occasionally, radio stations broadcast educational programs to schools.

The sad fact is that, radio programming is normally produced and presented by adults, and pushed down the domain of children to listen. The World Radio Forum denotes that, disinterest [by adult broadcasters] to represent youth has resulted in airing content that perpetuates youth stereotypes. Thus, maintains the Forum, "News stories on child rights issues may show youth as the cause of a problem . . . but rarely as part of a solution." Conversely, if a radio broadcaster includes the words of an injured child, describing how his village was attacked and how he became separated from his parents, the contextual reportage would give a more befitting story.

To reiterate the importance of contextual reporting, the Radio Manifesto, developed with backing from the World Radio Forum, has carved out declarations depicting youth radio aspirations and contribution to society. The following is part of youth radio Manifesto:

- We want to speak out against all forms of violence - killing, abduction, and sale of children, rape and every other kind of child abuse and exploitation.

- We want our voices to be included in denouncing war and in speaking out against the exploitation of children in armed conflict.

- We would like radio to give us the space for more smiles and less sadness and singing songs, laughter and play.

- We want our voices to be heard in the fight against Human Immuno-deficiency Virus (HIV) and Acquired Immune Deficiency Syndrome (AIDS).

- We need radio to bring tolerance to our world of different nations, religions and cultures.

Having fully adopted the manifesto, youth radio airs informational and educational and participatory programs. Definitely, youth radio produces programs to put into action children's right to education; to broadcast content that is considered appropriate for the age group; and to promote free education for under-privileged children. Needless to say, skilled youth radio manpower is vital in meeting the challenges and multicultural perspectives of listeners.

Youth radio skills were in display (2008) in Kenya following the riots that engulfed that country during the disputed presidential election. Barbara Dzeidzic (2009) recounts the event. On a bright day, a mob approached a seven-storey building belonging to a citizen of Kikuyu, the very tribe accused of stealing the election. Miraculously, youth radio, Pamoja FM, was located on the seventh floor. Barbara Dzeidzic (2009), high school teacher and graduate student majoring in international peace and conflict at American University (US), writes under the caption, "Pamoja FM Youth Radio and Civic Engagement." The radio youth enthusiast writes about 23-year old station manager, Antony Nyandiek, whom she reports as saying, "We told them this station belonged to all of them. They agreed and took their anger elsewhere." Nicknamed "Pamoja Radio Tower," Nairobi-based youth radio was proud to take credit for diffusing a conflict. Subsequently, an alliance was formed between Pamoja Radio Tower and Undugu Society to implement the Digital Story Telling Project.

To learn more about Pamoja FM, Barbara Dzeidzic accepted to be shown around. "Before arriving at the station, I had 
come up with a list of questions," Dzeidzic recollects. The graduate student was amazed that, among a busy staff of 15 , no one was more than 27 years old. While Dzeidzic was expecting answers to prepared questions, no staff member named or cited a single youth program. Instead, they named programs youth radio had presented with adults as target audience. Why? Pamoja FM believes addressing their problems or issues directly to adults will trigger interactive discussion. The staff believes youth radio training will enhance professionalism.

\subsection{Youth Training for Youth Radio}

The Broadcasting Service of the University of Illinois at Urbana-Champaign runs WILL-AM and WIL-FM stations that provide youth training. The Youth Media Workshop prides in "empowering economically diverse African American youth from public schools to make media and change social life." Students are taught how to produce radio documentaries that link their generation and the hip-hop generation to the civil rights and black power generations.

A multi-racial team of radio professionals teaches students from select public radio stations. Experienced students serve as mentors; local teachers and community leaders are part of the training team. Trainees learn to conduct library research; interview their families, peers, and community members; edit audio programs; present their findings at public events and conferences; think analytically; and lead youth discussion groups. The workshop empowers students to use radio to understand their history and to help build their communities. Another goal is to use radio in building self-esteem and stronger identities among youth.

In Kenya, the Youth Radio Trainer was held in Dadaab from July 2012 to April 2013. Working in partnership with Star FM (Nairobi) and the Dadaab Humanitarian Information Services (HIS), the training program addresses communication gaps between youth seeking humanitarian services and organizations providing these services. Participants receive training in developing communication between donors and receivers of services. Above all, the training makes it possible for youth to start radio stations as "spin-off" of Star FM in their communities. Acquired skills include designing, implementing, and overseeing aspects of a broadcast entity; learning to replicate program production and procedures; working with humanitarian agencies to produce specific messages; and liaising with local reporters and correspondents in completing productions and acquiring feedback.

Yumna Martin, CRF trainer/producer and Mike Rahfaldt, CRF executive director, have memories of a training workshop in 2011 organized by the CRF at the facilities of Greater Lebowakgomo FM. The trainees were part of high school students aspiring to become radio broadcasters. At the end of each day, the trainees reflected on their experiences. For the first time, 15-year old Thoriso Tladi was asked to speak in front of the group, but the female learner was scared and close to tears. It was a terrifying act, one that young people dread. But after a week of radio training, Thoriso overcame her fear to speak. She took every opportunity to make her voice heard. Thoriso said radio training built her confidence; it stimulated her to express her opinion. Yumna Martin and Mike Rahfaldt remember Thoriso's words: "It was really nice that we got to share our ideas with each other and expose our talents."

UNESCO organized a youth radio capacity building training course on November 19 - December 5, 2012, under the theme, "Empowering Local Radios with ICTs)." A total of 38 males and 38 females were trained on editorial, programming, and use of information, communication, and communication (ICT) in radio broadcasting. The international organization aimed at developing youth radio skills and to instill research and production techniques for participatory programming. Hands-on experience was provided at six participating radio stations: Mafeteng Radio (107.7), Jozi FM (105.8), Radio Atlantis (107.9), Bush Radio (89.5), Valley FM (88.8), and Radio Riverside (98.2).

\subsection{US Citizen Extols Youth Radio}

In fact, even adults have noticed advancement in youth radio programs. Kaitlin Parker (http://soundslikeaparker.com), journalist and student at the University of Southern California, testifies. After spending three months in Cape Town (South Africa), the radio practitioner was moved by the astuteness of youth radio broadcasters. The adult broadcaster reflects on the unique "soundscape;" daily Signal Hall Cannon; thundering "boom" at noon; minibus drivers yelling their destinations to potential street-side passengers; and constant chatter in English, Xhosa, Afrikaans and hybrid amongst 11 languages. "It's a steaming city in a country made of radio," writes Kaitlin. "Once a tool of division during apartheid, youth radio is now a means to bring millions of people together."

\subsection{Youth Radio Connects Classrooms}

Youth radio in South Africa has succeeded in "connecting classrooms." It connects young people across the country (and the world), facilitating cross-cultural dialogue about social issues. Pairing high school classrooms in different countries, UNICEF uses "audio pen pal" to allow young people to exchange audio letters and to debate on a regular basis. The intent of the program is to encourage young people to see the world from different perspectives and to inculcate communication skills.

\subsection{Youth and Hospital Radio}


In 2009, CRF launched Hospital Radio in Cape Town in conjunction with the Red Cross War Memorial Children's Hospital. Using audio recorders and microphones, Hospital Radio trains young patients to tell their stories on radio. Chronicling the long wait for kidney transplant, interviewing a doctor about treatment for severe burn, and "diarizing" life with a chronic heart and lung condition, form part of youth hospital radio stories. Radio reportage provides answers to questions about youth health; it makes it possible for ailing youth to share not only the conditions of their health, but also the anxiety of their wellness.

\subsection{Ingwavuma Rural Children's Radio Partnership}

Ingwavuma Rural Children's Radio Partnership serves northeast KwaZulu-Natal province. Youth in this area grow up amidst extreme poverty, risk of malaria, let alone devastating prevalence of HIV epidemic. In 2005, a partnership was established between the locally owned Zisize Educational Trust Company, Children's Institute (University of Cape Town), and a local primary school. The objective is for youth radio to emphasize the pain/struggle of growing up with AIDS.

CRF joined the partnership in 2009 with a series of radio workshops to boost youth radio capability to produce stories on youth. Ingwavuma radio shows are produced in isiZulu, the native language. Meanwhile, the community radio is now an invaluable tool for child advocacy, which includes recognizing and respecting children's rights. In 2009 and 2010, the Maputaland Community Radio show, "Abaqophi bakwaZisize Abakhanyayo" (Shining Reporters of Zisize), won UNICEF International Children's Day Broadcasting Award.

\subsection{Youth Shuga Radio}

South Africa's success in empowering youth through radio has permeated other countries on the continent. "Shuga: Love, Sex, Money," a spin-off of the award-wining television show, has become a popular radio drama reaching 45 million listeners in Cameroon, Democratic Republic of Congo, Kenya, Lesotho, South Africa, and Tanzania.

Shuga Radio takes cognizance that, sub-Saharan Africa has one of the highest rates of HIV infection in the world, and that young people are particularly vulnerable. Amid the characters associated with moving stories is Sofia (19), her sweetheart, Fally (20), Sofia's cousin, Amina (17), smooth talking and risk-taker, Karis (20), and a successful businesswoman and "sugar mommy," Riziki.

Originating from Pretoria (South Africa), Shuga Radio began broadcasting on June 27, 2012, giving listeners a realistic view of the lives of four young (fictional) characters aged 15-24. The series is based on a story about the young people's choices, dreams, friendships, challenges and triumphs in a world infested with HIV/AIDS, among other ominous challenges.

\subsection{Youth Radio Unleashes Kwaito Music}

Johannesburg (often called Joburg) is the seat of Kwaito Music. The novel "culture in music" is proudly styled "Rhythms of the Continent," and heard in Ivory Coast, Kenya, Malawi, Tanzania, and Zimbabwe. BBC (undated) did a story on Grant Clark as he travelled in Joburg to explore the origins of Kwaito music and to ascertain why it has become the voice of urban youth in new South Africa.

The transcontinental traveller admits that, the first thing people think when they hear about Joburg is high level of crime, disease, and violence. But beneath the unobtrusive surface is the bourgeoning reality. 21-year olds and under (about 50 percent of the country) have bonded with Kwaito music. In the words of Grant Clark, "the new sound of the township has helped shape a spirit of optimism and self-confidence," and "the youth can now speak openly throughout the lyrics."

The youth identify with Kwaito because it speaks to them. The music is a way of life. It is about the drug dealer in the ghetto everyone is looking up to because he drives nice looking cars. It is about the single mother struggling to raise her three children. In effect, Kwaito music is about ghetto life. In the view of jazz legend, Hugh Masekela, "Kwaito is going to be around for a long time. It's going to become a part of mainstream music. It's the core of township feeling."

Again, Kwaito owes its "raison d'être" to new South Africa when youth radio came into existence and was let to flourish with youth voices. One Kwaito music lover, Oscar waRona (as reported by Grant Clark), said, "This music came when Mandela was released," and continued, "we used to do tracks where we would ask, why is the divorce rate so high or why are little children being found in 'shabeens' drinking"? Regrettably, people (usually adults) "questioned" youth audacity to "question" older people. Notwithstanding, Kwaito music has infiltrated all forms of youth culture by way of radio, such as Youth FM in Joburg.

\subsection{Youth Radio Goes International}

The rich nature of African culture transcends territorial boundaries. It is this cultural transcendence that empowers youth radio to broadcast, live, "This Is Africa (TIA)," on Fridays. Simulcasting the show are youth radio stations in Nairobi 
(Kenya), Accra (Ghana), and Chicago (US). During the broadcast, local presenters animate 12 hours of youthful rhythms programmed to retire the books (or work) and to let the weekend begin. TIA plays the latest hit songs from all over Africa. The enticing radio stream can be heard online or TIA application (app). Another addition is live transmissions from Africa's hottest clubs and radio stations.

Friday "night-out" youth radio begins with Ghetto Radio in Nairobi, Kenya, from 5:00-10:00 p.m. (Eastern Standard Time); then moves to Kahuna Nite Club in Accra, Ghana, from 9:00 p.m.-11:00 p.m. (Eastern Standard Time); and progresses to Sonic Diaspora at the Shrine in Chicago, Illinois (US), from 11:00 p.m.-12:45 a.m. (Eastern Standard Time). Incidentally, the Sonic Diaspora nigh club is the hottest African "party venue" in the city.

\subsection{Youth Radio on Youth Health}

Although youth radio "rocks" intercontinentally, youth themselves must not just be in good health. They must make right choices about their health. The US Agency for International Development (USAID) in Sub-Saharan Africa (2006) assesses Education, Gender, General Health, and HIV/AIDS in the region. Under the headline, "Radio Show Encourages Youth to Pursue their Dreams and Preserve their Health," USAID refers to "Youth Alert Mix," the most popular youth radio magazine program that is "blazing across the airwaves."

In one youth radio episode, 18-year old Carol Tambala is reported to come from a poor family. Carol was pregnant at 16 and dropped out of school. During the following two years, she pleaded with her parents to go back to school, but to no avail.

Carol's ambition is to be a nurse. But she cannot attain her goal without education. "During my antenatal visits I met a lot of nurses and they told me I had to complete my education to pursue a career in nursing," Carol reminisces. She laments seeing her friends carry books on their way to school every morning, knowing very well "home stay" would lead her no where.

Then, one evening, Carol was listening to the program "Youth Alert Mix!" with her parents. Lo and behold, the topic presented in the program was "importance of going back to school after becoming pregnant." The young mothers in the program continued their studies and achieved their goals. Carol was ecstatic! Her mother, too, was moved. "The interview with a girl who had gone back to school was touching," Carol's mother conceded. "Soon after the program, we decided to allow our daughter to go back to school."

\subsection{Youth Radio Alert! Schools Programs}

USAID funds Youth Alert! The programs serve a dual purpose. First, the messages are intended to help the youth make wise decisions about their future and health. Second, the programs are aimed at promoting HIV prevention among young people. Moreover, the program targets secondary school youth using interactive capacity for role playing and participatory drama. In the final analysis, the program strives to educate and motivate youth to adopt responsible sexual behaviors.

Youth Alert! Mix (YAM) airs three times a week on youth radio fostering good decision-making and effective interpersonal communication. Youth Alert! Listeners Club targets 200 listening clubs on YAM. After the broadcast, listeners are asked to form smaller groups to discuss reproductive concerns raised in the broadcast. In Youth Alert! Peer Education, 160 exemplary teachers lead discussions on HIV/AIDS. In this connection, discussions take on youth radio and its effect on listeners and the community.

\subsection{Youth Radio's Effect on Youth}

What would youth radio be without effect? It is effect that illuminates youth radio functions and rationalizes its existence. It is, therefore, not surprising that Victor Brown Omovbude writes a radio commentary entitled, "My Life, Zeal, and Thoughts." Victor thinks life can be sweet or bitter. Sooner or later, the young writer acknowledges, individuals come to grips as to whether life is sweet or bitter.

Victor confesses that foolishness was key to the early failures in his life. Sooner than later, it dawned on him why success had eluded him. "Now I am different. Education has helped me - it gave me the ability to develop critical thinking." At 22, Victor leads production and dissemination of youth radio motivation groups. The latter encourage progressive planning for youth and meaningful life endeavors.

\subsection{Youth Radio and the Future}

That radio waves will crisscross the air as long as planet earth remains intact is unequivocal. In "Q\&A: Radio Gives Voices to South African Youth" on February 25, Joan Erakit (2013) reports on Lasedi Mogoatlhe. The latter is a youth radio supporter who has dedicated her life to "empowering African youth by helping them find a voice through radio journalism." 
Lasedi Mogoatlhe's comment is testimony that youth radio initiatives will continue in the future. Meanwhile, the challenges and inequalities facing youth are innumerable. So, the pervasiveness of youth problems requires youth voices to articulate them from their own standpoint. Correctly, youth radio must address adult corruption and misuse of abundant natural resources. With anticipated population growth, Lasedi Mogoatlhe comments: "Youth from rural environments are hungry for knowledge . . . and more focused at organizing themselves through radio."

Youth radio is looking beyond funding by the likes of CRF and UNICEF. Serendipitously (and with an eye to the future), seven campus radio stations in South Africa launched "Future Beats" on May 29, 2014. "Future Beats" is a Youth Development and HIV Prevention program in Joburg, embedded in the Multisectoral HIV/AIDS Prevention (MHIVP) initiative. Writing on the launching, Glowik (2014) notes the multi-year program funded by the Deutsche Gesellschaft für Internationale Zusammenarbeit (GIZ) and the Higher Education and Training HIV/AIDS Program (HEAIDS). HEAIDS considers youth concerns as important, prominent of which are health and youth radio.

As for youth education to prepare future leaders, the German-South African cooperation has plans to establish partnerships with university radio stations. The partnerships are to create awareness about HIV/AIDS, human rights, youth employment, alcohol and drug abuse. Formed partnerships will facilitate production and airing of youth radio programs.

Not oblivious to South Africa's youth aspirations, president Jacob Zuma has appointed a new National Youth Development Agency board. Stone (2013) credits the president with vision to address ever-mounting youth problems and challenges, which must be tackled by youth radio. A 37 million dollar annual budget is to undertake development projects to benefit youth. To this audience, targeted radio programming will only solidify their bond with radio.

Education is the foundation for youth advancement. There is every indication that radio education in South Africa will not slow down. As of 2014, the National Electronic Media Institute of South Africa does not contemplate relenting on training, after which trainees receive a National Certificate in Radio Production. The institute's slogan is, "Come and immerse yourself in the creative world of Radio."

No argument is worth making to forestall future generations. More youth will come to this world, and so on. Each youth generation will require that its problems or concerns to be attended to. The need to harness radio to the arduous task is unmistaken. And since youth training is to serve every generation, universities and institutes will continue to place training as their "raison d'être." And if youth are at the center of learning, so will youth be at the center of youth radio.

\section{Conclusion}

South Africa's youth utilize radio airwaves to address issues that affect them. Youth radio has benefitted from the liberalization of broadcasting regulations put in place during post-apartheid and championed by the Independent Broadcasting Authority (IBA). Consequently, IBA privatized six lucrative commercial stations in 1994, giving preference and incentives to previously disadvantaged black communities. Currently, there are about 200 independent (non-profit) community radio stations in South Africa; most of them provide youth training and production of youth programming. Of the 120 Community Radio Forum members, 88 are on-air radio practitioners.

As a public service, the country's 11 official languages get airtime, plus German, Hindi, Portuguese, and the San languages of !Xu and Khwe. Radio stations in South Africa fall into three categories: public service broadcasting, commercial broadcasting, and community radio stations. The country's public broadcaster, SABC, includes 5FM; Metro FM which broadcasts music targeting black youth; and Channel Africa (an external radio service) with service to African countries in several languages.

Youth radio takes its marching orders from the Radio Manifesto, a product of the World Radio Forum formed in 2014 and comprised of broadcasters and producers. The manifesto addresses conduct and professional standards for world radio broadcasters. Alfonso Gumucio-Dagron (2014) confesses that, young people have many attributes that are not necessarily on the adult agenda, and that providing youth an opportunity to get involved in agenda setting is a win-win for communities.

Organizations such as UNICEF and CRF continue to provide resources for youth radio training and to produce programs. Initiatives have led to youth empowerment through radio, as well as participation by youth in researching and producing programs at community radio stations. Notable programs include "connect radio with classrooms;" programs for youth patients in hospitals; programs for rural audiences (Ingwavuma Rural Children's Radio Partnership) to tackle HIV epidemic; plus radio drama (Youth Shuga Radio) on love, sex and money heard by 45 million listeners in Cameroon, Democratic Republic of Congo, Kenya, Lesotho, South Africa, and Tanzania.

Culturally, youth radio has unleashed Kwaito music, with Joburg as its base. Styled "Rhythms of the Continent," it is also heard in Ivory Coast, Kenya, Malawi, Tanzania, and Zimbabwe. Kwaito has become the cultural voice of South Africa's urban youth. Moreover, the program, "This Is Africa," heard on Fridays, is simulcast by radio stations in 
Nairobi (Kenya), Accra (Ghana), and Chicago (US). The broadcasts present 12 hours of youth rhythms on Fridays to "kick off" the weekend.

The future of South Africa's youth bond with radio is promising. In "Q\&A: Radio Gives Voices to South African Youth" on February 25, 2013, Joan Erakit reports on Lasedi Mogoatlhe. The latter is a youth radio supporter who has dedicated her life to "empowering African youth by helping them find a voice through radio journalism."

In the meantime, seven campus radio stations in South Africa launched "Future Beats" on May 29, 2014. "Future Beats" is a Youth Development and HIV Prevention program in Joburg, embedded in the Multisectoral HIV/AIDS Prevention (MHIVP) initiative. Glowik (2014) notes the multi-year program funded by the Deutsche Gesellschaft für Internationale Zusammenarbeit (GIZ) and Higher Education and Training HIV/AIDS Program (HEAIDS). As of 2014, the National Electronic Media Institute of South Africa affirmed offering continued youth radio production classes. The institute's slogan is, "Come and immerse yourself in the creative world of Radio."

\section{References}

Alfonso, G. D. (2014). "Forward" in the Radio Manifesto developed by the World Radio Forum.

Ashwin. (2014). www.voicesofyouth.org/en/posts/global-citizenship--2/www.childrensradiofundation.org/why-radio. Visited January 24, 2014.

BBC (undated). Kwaito: The Voice of the Youth.

Berelson, B. (1952). Content analysis in communication research. Glencoe, Ill: Free Press.

Dzeidzic, B. (2009). Advocacynet.org/wordpress-mu-bdziedzic/blog/2009/07/08/pamoja-fm-youth-radio-by-default/. Visited July 5, 2014.

Elihu, K., \& Lazarseld, P. (1955). Personal Influence. Glencoe, Ill: Free Press.

Erakit, J. (2013). Q\&A: Radio Gives Voices to South African Youth. Inter Press Service (IPS).

Glowik, S. (2014). 'Future Beats' launched in Johannesburg.

Kelto, A., \& Block, M. (2012). National Public Radio. www.npr.org. Visited November 28, 2013.

Kenya Youth Radio Trainer (Dadaad). http://www.internews.org/jobs. Visited June 10, 2014.

Krippendorff, K. (1980). Content analysis: An Introduction to its Methodology. Beverly Hills: Sage.

Marying, P. (2000). Qualitative Content Analysis. Forum: Qualitative Social Research, 1(2), Art 20, June.

Martin, Y., \& Rahfaldt, M. (2010-2011). The children's participation is in the South African Child Gauge, Children's Institute, University of Cape Town.

Merriam-Webster Dictionary. www.m-w.com. Visited August 3, 2014.

Stone, S. (2013). Zuma appoints new National Youth Agency Board. www.bdlive.co.za/national/2013/03/22/zuma-apoints-new-yuth-d. Visited April 28, 2014.

\section{(cc) BY}

This work is licensed under a Creative Commons Attribution 3.0 License. 